\title{
Direct Intercession Approach by Clinical Pharmacist to Manage Medication Related Problems for Enhanced Patient Care
}

\author{
Sushanta Kumar Das*, Rajesh A. Maheshwari \\ Department of Pharmacy, Sumandeep Vidyapeeth (Deemed to be University), Piparia, Vadodara, Gujarat, INDIA.
}

\begin{abstract}
Background: Medication related problems (MRPs) leads to patient harm and healthcare burden as develops frequently in general practice and hospital setup. To enhance therapeutic outcome; active intercessions by clinical pharmacist through meticulous prescription review to reduce prescription errors are strongly recommended. Studies in abroad shown that clinical pharmacist led medication review enhances therapeutic outcome through suitable therapeutic elucidation. In India, this practice restricted merely reporting but direct intercessions to modify the therapy rarely reported. Hence the present study is planned to provide appropriate and referred modification for identified MRPs as a direct patient care process with main axiom 'better patient care'. Methods: This 'prospective open-label observational clinical cohort' study conducted between August'19 and January'20 at Gandhi Hospital, Secunderabad, India. Collected cases simultaneously reviewed to identify MRP, thoroughly crossed matched with standard reference, justified and reported to doctor with suitable modification suggestions. Results: Result highlights; equal distribution of patient sex and vast distribution of age from neonates to elderly. Diagnosis has no co-relation on MRP development. Antibiotics, gastro-protective and anticoagulants are with maximum frequency to
\end{abstract}

develop MRPs and entail strong vigilance. Furthermore drug toxicity, drug duplication, wrong dose and prescribing errors are most recurrent appeared problems. Subsequently appropriate modifications were suggested for every identified MRP and were closely observed till discharge for final outcome. Conclusion: Certain MRPs are frequently emerging and needs tackling with proper management strategy. Our study further highlights about necessitate of clinical pharmacist intercession in optimizing drug therapy by providing proper medication information and same has been accepted and appreciated by various doctors.

Key words: Clinical pharmacist intercession, Enhanced patient care, Medication related problems.

Correspondence

Mr. Sushanta Kumar Das,

Ph.D Research Fellow, Department of Pharmacy, Sumandeep Vidyapeeth (Deemed to be University), Piparia, Vadodara, Gujarat, INDIA.

Email id: sushanta.das47@gmail.com

DOI: 10.5530/jyp.2022.14.21

\section{INTRODUCTION}

Medication related problems (MRPs) are defined as any preventable event that may cause or lead to inappropriate medication use or patient harm and such events may be related to professional practice, health care products, procedures and/or systems including; prescription writing and prescription order communication. ${ }^{[1]}$ Due to vast quantity of drugs and their numerous guidelines related to administration, it become almost unfeasible for the any doctor to follow those guidelines as a near perfect manner while writing a drug for a particular patient condition. These circumstances give rise to development of frequent MRPs in general practice and also in hospital setup. ${ }^{[2]}$ Furthermore to overcome such issues, few constructive steps can be adopted like; introducing automated systems or uniform prescribing charts in order to avoid transcription and omission errors. Along with this, feedback control system for each prescription and immediate review of prescriptions before dispensing or even before actual administration can be performed with the assistance of a clinical pharmacist, this process found to be beneficial for enhanced patient care in few institutions. Finally, prescription audits should be performed periodically to identify MRPs and suitable methods to overcome such issues. ${ }^{[2]}$ To enhance the therapeutic outcome of each patient an active intercessions by clinical pharmacist who are trained to review the appropriateness of prescribed medicine with primary aim to reduction in prescription errors and prescribing faults are strongly recommended. Studies conducted earlier in abroad have shown that clinical pharmacist led medication chart review enhances the therapeutic outcome by identifying and resolve these errors by providing suitable therapeutic solutions. ${ }^{[3-6]}$ Clinical Pharmacists are capable to play a significant role in identification and modification of MRPs by constant prescription review along with pharmacist's intervention based on patient interview and follow-up. This practice can reduce the number of readmissions and emergency department visits also. ${ }^{[7]}$ Similarly in India clinical pharmacist activities including MRP identification and reporting is well established but subsequent clinical pharmacist lead intercession of MRPs to modify the therapy are not much reported as the modification entirely lay in the hand of doctors only. Therefore, we have aimed to provide appropriate and referred alternative to identified MRPs so as to involve in direct patient care process. We have initiated this approach in different In-patient units of Gandhi hospital (a tertiary care multi super-specialty government medical college and hospital at Secunderabad) where MRPs was identified by the clinical pharmacist during medication chart review and same were reported instantaneously to the visiting doctor and subsequent modifications were suggested to resolve those errors as a clinical pharmacist intercession approach.

\section{MATERIALS AND METHODS}

This 'prospective open-label observational clinical cohort' study was conducted between August 2019 and January 2020 at different in-patient units of Pediatrics, General Medicine, General Surgery, Obstetrics and Gynecology, Gastroenterology and Psychiatry departments of Gandhi Hospital, Secunderabad, Telangana, India, after obtaining necessary approval and permission (IEC approval No- CMRCP/IEC/2019-20/02).

This is an open access article distributed under the terms of the Creative Commons Attribution-NonCommercial-ShareAlike 4.0 License, which allows others to remix, tweak, and build upon the work non-commercially, as long as the author is credited and the new creations are licensed under the identical terms. 
In-patient units of selected departments were visited on a daily basis to collect cases for this study according to inclusion criteria which includes confirmed cases of MRP present in the In-patient department along with complete medical information till discharge of all ages and genders. Cases admitted due to preadmission MRPs, cases with pre-existing medication issues were excluded from the study. Cases of pregnant women were also excluded from the study as they are frequently present with nausea, vomiting, peripheral edema, decreased hemoglobin level etc. which makes the judgement difficult whether this is due to drug related or physiological. To conduct the study in a proper manner, we visited the in-patient units of different departments on a regular basis and review individual patient's case report carefully to identify any drug related problems. Once any prescription was suspected for MRP it was thoroughly analyzed and with the support of various reference resources to justify the occurrence of MRP. Subsequently reported the same to the visiting doctor to confirm and a suitable referred alternative suggestion was also provided to manage and overcome the identified MRP. Modified cases were updated daily until discharge and discharge summery was also collected. To continue this process of direct patient care through intercession approach regular interaction with doctors was carried out regarding authentication of collected MRPs and development of a suitable management strategy was always the main motto. Finally collected cases were interpreted to extract the data according to various category and parameters to obtain the result.

\section{RESULTS}

During the study period we have confirmed a total of 70 cases according to inclusion and exclusion criteria. In those case definite MRP were established and subsequently suggested modifications to alter the therapy were accepted and modified accordingly. Demographic distribution (Table 1) of collected cases shows male and female were almost equal in number. In age wise distribution, we found that patient was present in almost all age groups, amongst them $16-41$ years were predominant. We have also identified cases where patient age was between 1 month and less than 1 year (05) and 65 years and above (08). Admission

Table 1: Demographic distribution of collected cases.

\begin{tabular}{cccc}
\hline \multicolumn{4}{c}{ Gender wise distribution of collected cases } \\
\hline SI No & Sex & No of cases & Percentage (\%) \\
\hline 1 & Female & 36 & 51 \\
2 & Male & 34 & 49 \\
\hline \multicolumn{4}{c}{ Age wise distribution of collected cases } \\
\hline SI No & Age group & No of cases & Percentage (\%) \\
\hline 1 & Up to 15 years & 09 & 13 \\
2 & 16 years - 40 years & 31 & 44 \\
3 & 41 years - 60 years & 17 & 24 \\
4 & More than 60 years & 13 & 19 \\
\hline \multicolumn{4}{c}{ Admission department wise distribution of collected cases } \\
\hline SI No & Department & No of cases & Percentage (\%) \\
\hline 1 & General Medicine & 38 & 54 \\
2 & General Surgery & 10 & 14 \\
3 & Pediatrics & 08 & 11 \\
4 & Gynecology & 07 & 10 \\
5 & Orthopedics & 05 & 07 \\
6 & Gastroenterology & 01 & 02 \\
7 & Psychiatry & 01 & 02 \\
\hline
\end{tabular}

department wise distribution highlights that, General medicine account for almost half of the collected cases, this predominately because general medicine department has highest number of bed strength in the hospital. Diagnosis wise distribution does not provide any specific condition for occurrence of MRP as a long list of 45 different diagnoses was identified in the collected cases (Table 2).

Table 2: Diagnosis wise distribution of collected cases.

\begin{tabular}{|c|c|c|c|}
\hline \multicolumn{4}{|c|}{ Diagnosis wise distribution of collected cases } \\
\hline SI No & Diagnosis & $\begin{array}{l}\text { No of } \\
\text { cases }\end{array}$ & Percentage (\%) \\
\hline 1 & Anemia & 07 & 10 \\
\hline 2 & Fracture & 05 & 07 \\
\hline 3 & Seizure & 04 & 05 \\
\hline 4 & Dengue & 03 & 04 \\
\hline 5 & Drug Induced Bleeding & 03 & 04 \\
\hline 6 & Thrombocytopenia & 03 & 04 \\
\hline 7 & Cirrhosis of Liver & 02 & \\
\hline 8 & CVA & 02 & \\
\hline 9 & Encephalopathy & 02 & Around $03 \%$ \\
\hline 10 & Fibroid Uterus & 02 & \\
\hline 11 & Left LL Wet Gangrene & 02 & \\
\hline 12 & LRTI & 02 & \\
\hline 13 & Abnormal Uterine Bleeding & 01 & \\
\hline 14 & Abusive Behavior & 01 & \\
\hline 15 & Acute Appendicitis & 01 & \\
\hline 16 & Acute Febrile Illness & 01 & \\
\hline 17 & Acute Gastroenteritis & 01 & \\
\hline 18 & Acute Liver Injury & 01 & \\
\hline 19 & Acute Meningitis & 01 & \\
\hline 20 & Alcohol Induced Cerebellitis & 01 & \\
\hline 21 & B/L Pneumonitis with Sepsis & 01 & \\
\hline 22 & Bicytopenia & 01 & \\
\hline 23 & Cellulites & 01 & \\
\hline 24 & $\begin{array}{c}\text { Cerebral Sinus Venous Thrombosis } \\
\text { with Abortion }\end{array}$ & 01 & \\
\hline 25 & Cholelithiasis & 01 & \\
\hline 26 & Chronic Kidney Disease & 01 & \\
\hline 27 & Duodenal Ulcer & 01 & \\
\hline 28 & DVT & 01 & \\
\hline 29 & Drug Induced Extrapyrimidal Effects & 01 & $\begin{array}{l}\text { Around } 1.4 \% \\
\text { each }\end{array}$ \\
\hline 30 & Ectopic Pregnancy & 01 & \\
\hline 31 & Fistula & 01 & \\
\hline 32 & Full term Vaginal Delivery & 01 & \\
\hline 33 & Gastric Carcinoma & 01 & \\
\hline 34 & Hypothyroidism & 01 & \\
\hline 35 & Jaundice & 01 & \\
\hline 36 & Left foot dry gangrene & 01 & \\
\hline 37 & Liver Abscess & 01 & \\
\hline 38 & Paracetamol poisoning & 01 & \\
\hline 39 & Peripheral vascular disease & 01 & \\
\hline 40 & Pneumatic effusion & 01 & \\
\hline 41 & Post menopausal bleeding & 01 & \\
\hline 42 & Pyrexia & 01 & \\
\hline 43 & $\begin{array}{l}\text { Sub Serosal Fibroid with Severe } \\
\text { Anemia }\end{array}$ & 01 & \\
\hline 44 & Thrombocytopenia with Fever & 01 & \\
\hline 45 & Vaccine Induced Seizure & 01 & \\
\hline
\end{tabular}


Our study demonstrates 10 different types of MRPs developed in the confirmed cases. Drug toxicity, wrong dose, prescribing error and drug duplication was the most common MRP with almost 20\% occurrence for each. Untreated indication, prescribing error with wrong dose and improper drug selection were next to follow. Administration error, drug without indication and drug-drug interaction was one each (Table 3).

From the study we identified the involvement various drugs in the reported MRPs. This data shows numerous drugs were involved into the development of MRPs and we had a total number of 46 different drugs out of all collected cases. Pantoprazole had the highest contribution followed by Ceftriaxone rest all drugs had almost single contribution. Upon pharmacological distribution of the involved drugs highlights that, antibiotics are the front runner $(28 \%)$ to cause MRPs, followed by gastro protective agents (21\%). Even supplements (8\%) also found along with anticoagulants (7\%) (Table 4).

For each collected MRPs we have provided standard and justified reference to establish our point and same was discussed with the visiting doctor. We have briefly described the individual identified MRPs and subsequent modification and/or suggestion provided to overcome the problems (Table 5).

\section{DISCUSSION}

Our study clearly highlights the necessity to include clinical pharmacist to identify MRPs and to resolve them before it causes patient Harm. Previously published reports also stated that, to keep away from any untoward medication related issues; suitable strategy need to exercise like inclusion of clinical pharmacist especially for pediatric and geriatric population patient group for proper prescription monitoring and subsequent modification before the drug is administered to avoid any additional healthcare burden. ${ }^{[8,9]}$ Throughout the study, cases with definite MRPs have been collected from various departments. Furthermore, General Medicine being the largest department in terms of highest number of admission and also the bed capacity, we also found maximum cases from there only. Diagnosis wise distribution of collected cases shows a wide range of conditions with Anemia as the maximum number. But our study highlights that diagnosis has no direct association in the development of MRP.

In our study few cases were with two different types of MRPs occurred in a same case (Prescribing error with Wrong dose together) and therefore we have enlisted them as a separate MRP type. Condition such as Drug Toxicity, Prescribing Error, Wrong Dose and Drug Duplication were most common MRPs identified in our study. Drug Toxicity, Wrong Dose and Drug Duplication are such circumstances which may even

Table 3: Distribution of different types of MRPs.

\begin{tabular}{cccc}
\hline SI No & Types of MRPs & No of cases & $\%$ \\
\hline 1 & Drug Toxicity & 14 & 20 \\
2 & Wrong Dose & 14 & 20 \\
3 & Prescribing Error & 13 & 18 \\
4 & Drug Duplication & 13 & 18 \\
5 & Untreated Indication & 05 & 07 \\
6 & Prescribing Error with Wrong dose & 04 & 05 \\
7 & Improper Drug Selection & 04 & 05 \\
8 & Administration Error & 01 & \\
9 & Drug without Indication & 01 & Around \\
10 & Drug-Drug Interaction & 01 & $1.4 \%$ each \\
\hline
\end{tabular}

Table 4: Distribution of different drugs involved in MRPs.

\begin{tabular}{|c|c|c|c|}
\hline \multicolumn{4}{|c|}{ Frequency of drugs involved in MRPs in individual case } \\
\hline SI No & Drug name & Frequency & $\%$ \\
\hline 1 & Pantoprazole and Ranitidine & 07 & 10 \\
\hline 2 & Ceftriaxone & 05 & 07 \\
\hline 3 & Pantoprazole & 05 & 07 \\
\hline 4 & Metronidazole & 04 & 05 \\
\hline 5 & Sodium bicarbonate & 03 & 04 \\
\hline 6 & Apixaban & 02 & \\
\hline 7 & Cefotaxime & 02 & Around \\
\hline 8 & Ondansetron & 02 & $03 \%$ each \\
\hline 9 & Paracetamol & 02 & \\
\hline 10 & Nicoumalone & 01 & \\
\hline 11 & Alprazolam and Tramadol & 01 & \\
\hline 12 & Ambroxyl & 01 & \\
\hline 13 & Amikacin & 01 & \\
\hline 14 & Amoxycillin with Cavunate & 01 & \\
\hline 15 & $\begin{array}{l}\text { Amoxycillin with Cavunate } \\
\text { and Cefixim }\end{array}$ & 01 & \\
\hline 16 & Aspirin and Atorvastatin & 01 & \\
\hline 17 & Cefixim & 01 & \\
\hline 18 & Carica Papaya & 01 & \\
\hline 19 & Carbamazepine & 01 & \\
\hline 20 & Cefotaxime and Ceftriaxone & 01 & \\
\hline 21 & $\begin{array}{c}\text { Ceftriaxone and Pipericillin } \\
\text { with Tazobactum }\end{array}$ & 01 & \\
\hline 22 & Doxycyclin & 01 & \\
\hline 23 & Enalapril & 01 & \\
\hline 24 & Furosemide & 01 & \\
\hline 25 & Haloperidol & 01 & \\
\hline 26 & Heparin & 01 & \\
\hline 27 & Insulin & 01 & Around \\
\hline 28 & Iron Folic Acid & 01 & $1.4 \%$ each \\
\hline 29 & Multivitamin with Mineral & 01 & \\
\hline 30 & Nifedipine & 01 & \\
\hline 31 & $\begin{array}{l}\text { Pantoprazole, Vitamin B } \\
\text { complex and Furosemide }\end{array}$ & 01 & \\
\hline 32 & Pentoxyphylin & 01 & \\
\hline 33 & Phenytoin & 01 & \\
\hline 34 & Pipericilin with Tazobactum & 01 & \\
\hline 35 & Potassium chloride & 01 & \\
\hline 36 & Ranitidine & 01 & \\
\hline 37 & S-Adenosyl Methionine & 01 & \\
\hline 38 & Sucralfate with Oxetacain & 01 & \\
\hline 39 & Sodium valproate & 01 & \\
\hline 40 & Thyroxin & 01 & \\
\hline 41 & Tramadol & 01 & \\
\hline 42 & Tranexamic acid & 01 & \\
\hline 43 & Tramadol and Ondansetron & 01 & \\
\hline 44 & Vancomycin & 01 & \\
\hline 45 & Vitamin B12 & 01 & \\
\hline 46 & Warfarin & 01 & \\
\hline
\end{tabular}


Table 4: Cont'd.

\begin{tabular}{|c|c|c|c|}
\hline \multicolumn{4}{|c|}{ Distribution of involved drugs as per their Pharmacological class in MRPs } \\
\hline SI No & Drug Class & Frequency & $\begin{array}{c}\text { Percentage } \\
\text { (\%) }\end{array}$ \\
\hline 1 & Antibiotic(s) & 20 & 28 \\
\hline 2 & Gastro Protective agents & 15 & 21 \\
\hline 3 & Supplements & 06 & 08 \\
\hline 4 & Anticoagulant & 05 & 07 \\
\hline 5 & Antiepileptic & 03 & 04 \\
\hline 6 & Antiemetic & 03 & 04 \\
\hline 7 & Analgesic & 03 & 04 \\
\hline 8 & Antacid & 03 & \\
\hline 9 & Diuretic & 02 & Around \\
\hline 10 & Anti Hypertensive & 02 & $03 \%$ each \\
\hline 11 & Antipyretic & 02 & \\
\hline 12 & Anti diabetic & 01 & \\
\hline 13 & Antiplatelet & 01 & \\
\hline 14 & Anti Schizophrenic & 01 & \\
\hline 15 & Electrolyte & 01 & \\
\hline 16 & Haemostatic & 01 & Around \\
\hline 17 & Hormone & 01 & $1.4 \%$ each \\
\hline 18 & Lipid lowering agent & 01 & \\
\hline 19 & Mucolytic & 01 & \\
\hline 20 & Natural product & 01 & \\
\hline 21 & Sedative & 01 & \\
\hline
\end{tabular}

lead to serious patient harm. ${ }^{[10-12]}$ Therefore our direct intercession to identify those issues, cross matched with standard reference, guidelines and succeeding modification suggestion were a timely action as a direct patient care approach. For all these cases, scrutiny and discussion with doctor were fruitful as they accepted our suggestions and alter the medication accordingly. This has greatly enhanced the therapeutic outcome of the patient with minimizing further complications. Importance of inclusion of pharmacist led intervention has proven efficacy in terms of patient benefit and also to reduce medication error. ${ }^{[13,14]}$ Prescribing Errors were mainly due to writing mistake and mostly double writing of same medicine, those are not much of hazardous as the nurses administer only one even if written as two times. But as per our identification we have thoroughly scrutinize them and as well discussed with doctor for withdrawal of one from the prescription.

But if we investigate the drug classification, whole scenario changes dramatically and we found that antibiotics are the drugs that appeared to develop maximum number of MRPs being one of the most talked global healthcare issues. ${ }^{[15]}$ followed by gastro protective agents. Supplements and anticoagulant are the other two classes which are in forefront to develop MRPs. Similar finding was also reported previously. ${ }^{[16]}$ This finding clearly shows that antibiotics still remain a matter of concern while prescribing and a strong vigilant analysis of every antibiotic prescribed should be one of the keys focuses of every clinical pharmacist while reviewing the patient case sheet. By performing the direct approach to manage those MRPs, we strongly believe that we have achieved our targeted goal to enhance patient care.

In the management approach towards identified MRPs, we have thoroughly discussed with the doctors for every single identified
MRP and also provided supportive evidence and justified information support obtained from either textbook or from standard medical journal/websites. With our vigorous approach individual medication related problems were accepted and our service was appreciated. This intercession activities by clinical pharmacist shows a positive outcome even on the doctors also, they are well aware about various medication related problems but due to their time constrain and huge patient burden especially in a government hospital setup, made them restricted to focus in this particular arena. Support by clinical pharmacist in this particular pitch has provided them an opportunity to rectify their prescription error as they also have the motto to provide better patient care. As both of our aim matched, we could enhance the overall management approach together.

We also found certain cases in which rectification was not done on the patient case sheet even though after discussion MRPs were accepted. The main reason for this was identified as: As prescribed by the unit chief/ Senior professor, therefore Post Graduate Trainees were not able to modify those without prior permission and thus it may take some additional time to alter, non-availability of drugs in the unit, doctors were not adequately confident about clinical pharmacist's intercession suggestion to alter a drug therapy or doctors may have diverse or improved verdict about a reported MRP. We did not include those cases for our study; instead, we have continued our dialogue with the doctors and provided them additional information about those MRPs to establish our position so as to continue the approach for future development. This study was performed in a government hospital setup with various limitations. However, since the reduction of prescribing errors and related harm was significant in this study, and the results corresponded to earlier findings, it is highly probable that the beneficial effects could be copied in other clinical settings by the on-ward employment of clinical pharmacists.

\section{CONCLUSION}

Clinical pharmacists are uniquely trained to review prescription medicine and also to intercession with a main axiom as better patient care. From this study we highlighted that certain medication related problems are frequently came into sight and those needs to be addressed with proper management strategy. Our study further highlights about necessitate of clinical pharmacist intercession in optimizing drug therapy by providing proper medication information and same has been accepted and appreciated by various doctors. We could conclude that direct intercession approach by clinical pharmacist has great outcome to manage MRPs for enhanced patient care.

\section{ACKNOWLEDGEMENT}

Authors whole heartedly convey their sincere gratitude to the doctors of various departments of Gandhi Hospital, Secunderabad for their constant support and participation in the case collection and subsequent discussion about various MRPs and their modification process. Without their support this works wouldn't have completed successfully.

\section{CONFLICT OF INTEREST}

The authors declare that there is no conflict of interest.

\section{ABBREVIATIONS}

CABG: Coronary Artery Bypass Graphting; Tab: Tablet; PT: Prothrombin time; INR: International Normalized Ratio; mg: Milligram; SJS: Steven Johnson Syndrome; SOS: Whenever Necessary; GRBS: Generalized Random Blood Sugar; dl: Deciliter; TID: Trice In a Day; DNS: Dextrose Normal Saline; gm: Gram; Inj: Injection; OD: Once in a Day; BD: 


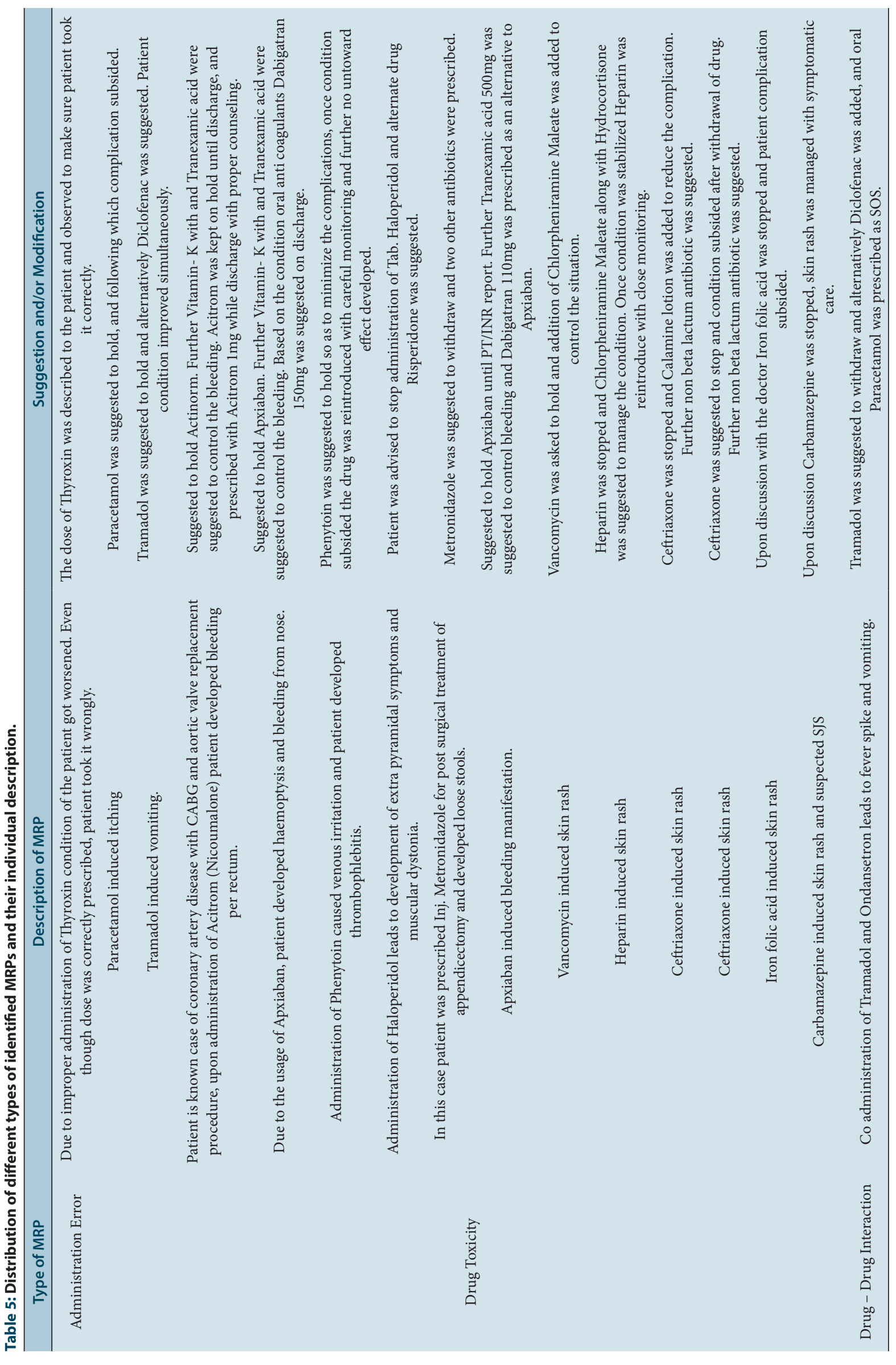




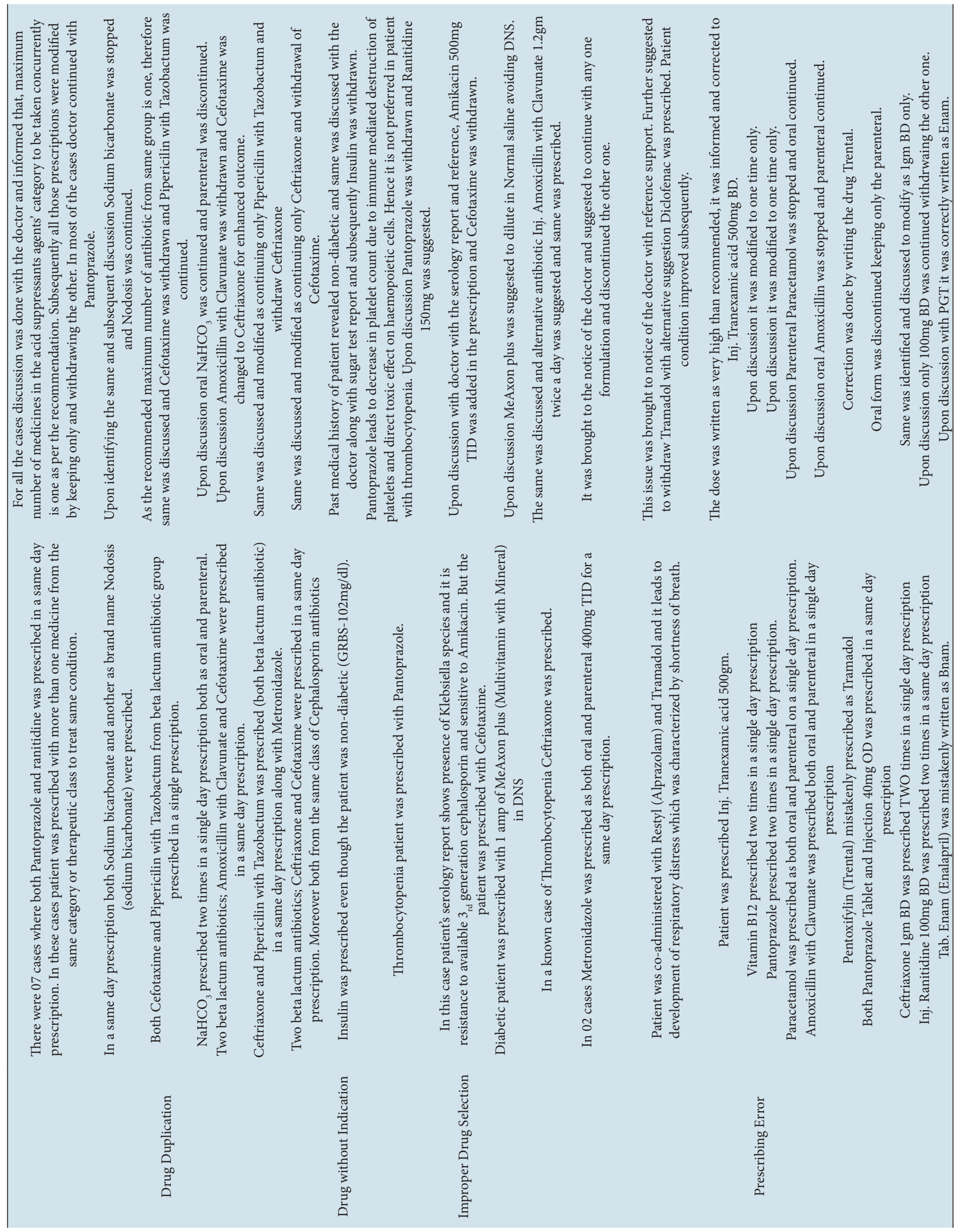




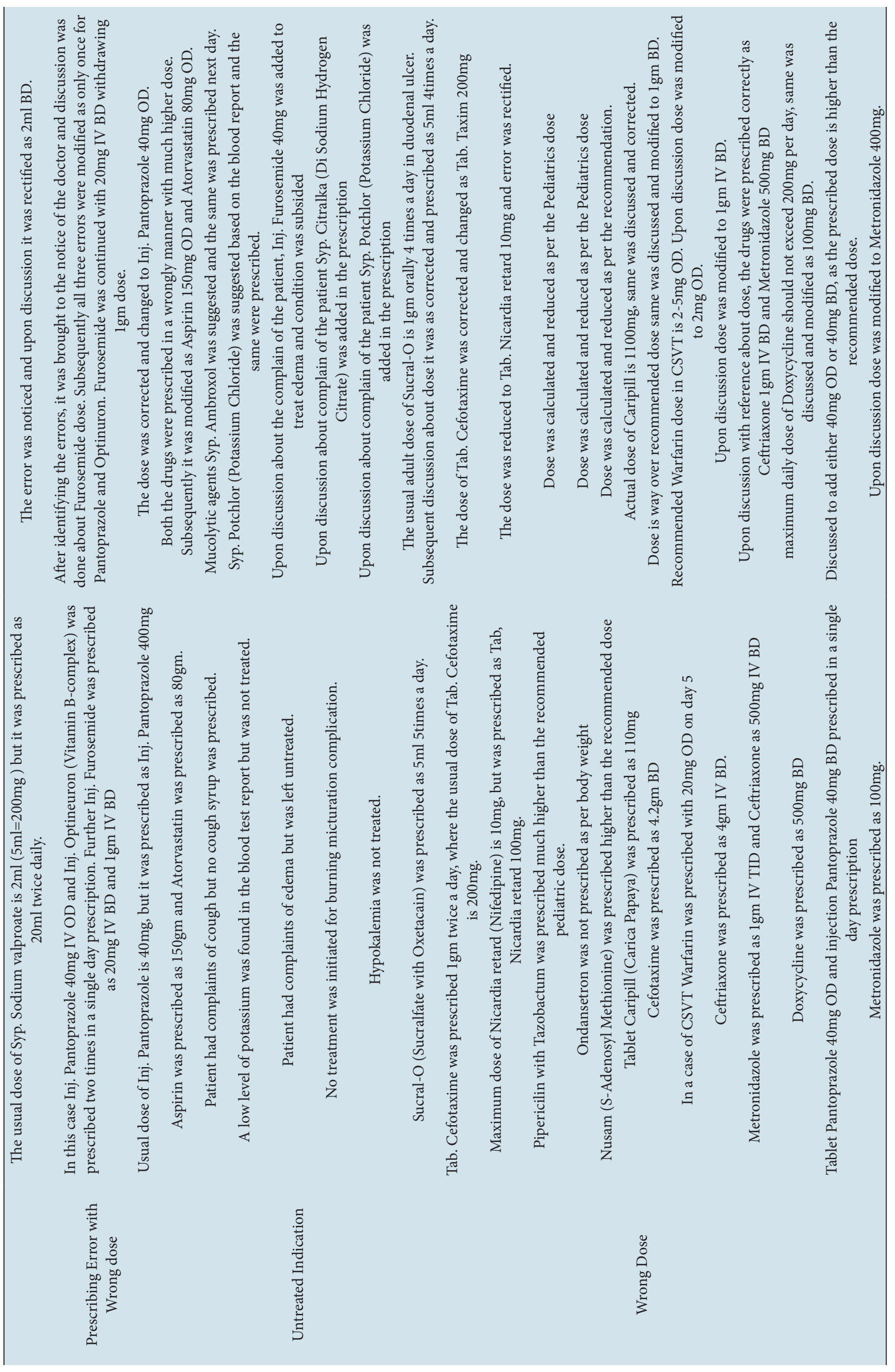


Twice in a Day; TID: Thrice in a Day; PGT: Post Graduate Trainee; Syp: Syrup; ml, Milliliter; IV, Intravenous; CSVT, Cerebral Venous Sinus Thrombosis.

\section{REFERENCES}

1. WHO. Medication errors: Technical series on safer primary care. Available from: http://apps.who.int/iris/bitstream/handle/10665/252274/9789241511643-eng.pd f;jsessionid=E4D3A15C83CBF2F92C45A2381DE64CE8? sequence=1. Geneva: World Health Organization; 2016. 28 p. Report no: 9.

2. Velo GP, Minuz P. Medication errors: Prescribing faults and prescription errors. Br J Clin Pharmacol. 2009;67(6):624-8. doi: 10.1111/j.1365-2125.2009.03425.x. PMID 19594530.

3. LeeT, Davis E, Kielly J. Clinical impact of a pharmacist-led inpatient anticoagulation service: A review of the literature. Integr Pharm Res Pract. 2016;5:53-63. doi: 10.2147/IPRP.S93312. eCollection. PMID 29354540.

4. Pfister B, Jonsson J, Gustafsson M. Drug-related problems and medication reviews among old people with dementia. BMC Pharmacol Toxicol. 2017;18(1):52. doi: 10.1186/s40360-017-0157-2. PMID 28655357.

5. Garin N, Sole N, Lucas B, Matas L, Moras D, Rodrigo-Troyano AR, et al. Drug related problems in clinical practice: A cross-sectional study on their prevalence, risk factors and associated pharmaceutical interventions. Sci Rep. 2021;11(1):883. doi: 10.1038/s41598-020-80560-2. PMID 33441854.

6. Wolf C, Pauly A, Mayr A, Grömer T, Lenz B, Kornhuber J, et al. Pharmacist-led medication reviews to identify and collaboratively resolve drug-related problems in psychiatry - A controlled, clinical trial. PLOS ONE. 2015;10(11):e0142011. doi: 10.1371/journal.pone.0142011. PMID 26544202.

7. Ravn-Nielsen LV, Duckert ML, Lund ML, Henriksen JP, Nielsen ML, Eriksen CS, et al. Effect of an in-hospital multifaceted clinical pharmacist intervention on the risk of readmission: A randomized clinical trial. JAMA Intern Med. 2018;178(3):375-82. doi: 10.1001/jamainternmed.2017.8274. PMID 29379953.
8. Balakrishnan RP, Ravichandran R, Dillibatcha JS, Ravi AL, Sam NC Nuthalapati R. Clinical pharmacists' role in paediatric patients' medical care. Int J Contemp Pediatr. 2020;7(12):2416-20. doi: 10.18203/2349-3291. ijcp20205110.

9. Campbell AM, Coley KC, Corbo JM, DeLellis TM, Joseph M, Thorpe CT, et al. Pharmacist-Led Drug Therapy Problem Management in an Inter professional Geriatric Care Continuum: A Subset of the PIVOTS Group. Am Health Drug Benefits. 2018;11(9):469-78. PMID 30746018, PMCID PMC6322592.

10. Rodziewicz TL, Houseman B, Hipskind JE. Medical error reduction and prevention. Stat pearls [internet]. Treasure Island, (FL): Stat Pearls Publishing 2021. Available from: https://www.ncbi.nlm.nih.gov/books/NBK499956/ [cited 20/1/2022].

11. Rahmanzade R, Cabrera Diaz FC, Zaugg C, Schuetz P, Salili AR. Therapeutic duplication of anticoagulants: A retrospective study of frequency and consequences in a tertiary referral hospital. Thromb J. 2020;18:14. doi: 10.1186/ s12959-020-00227-w. PMID 32774174.

12. Williams DJP. Medication errors. JR Coll Physicians Edinb The. 2007;37(4):343-6.

13. Chia-Chi C, Fei-Yuan H, Li-Jiuan S, Chien-Chih W. The cost-saving effect and prevention of medication errors by clinical pharmacist intervention in a nephrology unit. Medicine. 2017:96:34:(e7883). doi: 10.1097/MD.0000000000007883, doi: 10.1097/MD.0000000000007883.

14. Omboni S, Caserini M. Effectiveness of pharmacist's intervention in the management of cardiovascular diseases. Open Heart. 2018:5(1):e000687. doi: 10.1136/openhrt-2017-000687. PMID 29344376.

15. Blix HS, Viktil KK, Moger TA, Reikvam A. Risk of drug-related problems for various antibiotics in hospital: Assessment by use of a novel method. Pharmacoepidemiol Drug Saf. 2008;17(8):834-41. doi: 10.1002/pds.1595, PMID 18381745.

16. Babelghaith SD, Wajid S, Alrabiah Z, Othiq MAM, Alghadeer S, Alhossan A, et al. Drug-related problems and pharmacist intervention at a general hospital in the Jazan region, Saudi Arabia. Risk Manag Healthc Policy. 2020;13:373-8. doi: 10.2147/RMHP.S247686. PMID 32547271.

Article History: Received: 27-09-2021; Revised: 23-11-2021; Accepted: 10-01-2022

Cite this article: Das SK, Maheshwari RA. Direct Intercession Approach by Clinical Pharmacist to Manage Medication Related Problems for Enhanced Patient Care. J Young Pharm. 2022;14(1):110-7. 